and medication were recorded. Pain and fatigue were measured by the Visual Analogue Scale (VAS), anxiety and depression were assessed using the Hospital Anxiety and Depression Scale (HADS), and sleep quality was assessed using the Pittsburgh Sleep Quality Index. SB was measured using the ActivPAL4 ${ }^{\text {TM }}$ activity monitor, over a 7-day wear period. Descriptive statistics were calculated to describe participant characteristics. Relationships between clinical characteristics and SB were examined using Pearson's correlation coefficients and regression analyses.

Results: $\mathrm{N}=76$ participants enrolled in the study with valid data provided by $\mathrm{N}=72$ participants. Mean age of participants was 61.5years (SD10.6) and the majority $63 \%(n=47)$ were female. Participant mean disease duration was 17.8years (SD10.9). Mean SB time was 533.7 (SD100.1) minutes (8.9 hours per day/59.9\% of waking hours). Mean sleep quality score was 7.2 (SD5.0) (Table 1). Correlation analysis and regression analysis found no significant correlation between sleep quality and SB variables. Regression analysis demonstrated positive statistical associations for SB time and body mass index ( $p$-value $=0.03846, R^{2}=0.05143$ ), SB time and pain VAS ( $p$-value $=0.009261, R^{2}=0.07987$ ), SB time and HADS $\left(p\right.$-value $\left.=0.009721, R^{2}=0.08097\right)$ and SB time and HADSD $(p$-value $=0.01932$, $\mathrm{R}^{2}=0.0643$ ).

Conclusion: We found high levels of sedentary behavior and poor sleep quality in people who have RA, however no statistically significant relationship was found in this study. Future research should further explore the complex associations between sedentary behavior and sleep quality in people who have RA.

REFERENCES:

[1] Carmona L, et al. Rheumatoid arthritis. Best Pract Res Clin Rheumatol 2010;24:733-745.

[2] Anon. Letter to the editor: standardized use of the terms "sedentary" and "sedentary behaviours". Appl Physiol Nutr Metab = Physiol Appl Nutr Metab 2012;37:540-542.

[3] Fenton, S.A.M. et al. Sedentary behaviour is associated with increased longterm cardiovascular risk in patients with rheumatoid arthritis independently of moderate-to-vigorous physical activity. BMC Musculoskelet Disord 18, 131 (2017).

[4] McKenna S, et al. Sleep and physical activity: a cross-sectional objective profile of people with rheumatoid arthritis. Rheumatol Int. 2018 May;38(5):845-853.

[5] Grabovac, I., et al. 2018. Sleep quality in patients with rheumatoid arthritis and associations with pain, disability, disease duration, and activity. Journal of clinical medicine, $7(10) 336$.

Table 1. Sleep quality in people who have RA

\begin{tabular}{ll}
\hline Sleep variable & \\
\hline Bed Time N(\%) & \\
$\quad$ before 10pm & $13(18 \%)$ \\
$10 p m-12 p m$ & $43(60 \%)$ \\
after 12pm & $16(22 \%)$ \\
Hours Sleep mean(SD) & $6.56(1.54)$ \\
Fall Asleep minutes mean(SD) & $33.3(27.7)$ \\
Night Waking N(\%) & $45(63 \%)$ \\
Self-Rate Sleep mean(SD) & $2.74(0.90)$ \\
Hours Sleep mean(SD) & $6.56(1.54)$
\end{tabular}

Disclosure of Interests: None declared

DOI: 10.1136/annrheumdis-2021-eular.641

\section{POS1466-HPR IMPACT OF COVID-19 PANDEMIC ON ADHERENCE BEHAVIOR OF LATIN-AMERICAN PATIENTS WITH RHEUMATIC DISEASES}

I. A. Moreno-Arquieta ${ }^{1}$, G. G. Sánchez Mendieta ${ }^{1}$, D. E. Flores Alvarado ${ }^{1}$, J. A. Esquivel Valerio ${ }^{1}$, D. Á. Galarza-Delgado ${ }^{1} .{ }^{1}$ Dr. José Eleuterio González (Gonzalitos) 235, Rheumatology, Monterrey, Mexico

Background: One of the greatest challenges of the COVID-19 pandemic for rheumatologists concerns the patient's adherence to treatment (1). The impact of poor adherence on the effectiveness of chronic disease treatment is severe in terms of poorer health outcomes and increased health care costs (2). Information regarding covid-19 on adherence behavior in Latin-American is scarce. Objectives: The aim of this study is to describe impact of COVID-19 outbreak on adherence behavior in Latin-American population with rheumatic diseases. Methods: We carried out a descriptive, cross-sectional, self-report study through voluntary telephonic survey, to determine adherence behaviors during the COVID-19 pandemic, from September $9^{\text {th }}, 2020$ to November $19^{\text {th }}, 2020$, for consecutive patients of the outpatient rheumatology clinic in the Hospital Universitario (Monterrey, Nuevo Leon, Mexico), which serves a resource limited population that lack access to health insurance, from five neighboring states. A 17-items survey was designed. Baseline demographics that were collected included age, sex, rheumatologic diagnosis, current medications and patient perception of disease control. Patients were asked if they continued follow-up care last prescribed therapy and reasons. Also, the survey assessed whether patients had any issues with medication supply and where they were obtaining information about covid-19 (could choose as many options as applicable). Transferred to SPSS for analysis for descriptive statistics.

Results: A total of 150 patients were called, the survey response rate was $54.6 \%$ $(n=82)$, with a mean completion time of 10 minutes. The mean $+/-S D$ age of the participants was $52+/-15.9$ years, and $95 \%$ were female. The most common self-reported diagnoses were rheumatoid arthritis (RA) (13.4\%) and systemic lupus erythematosus (SLE) (13.4\%) [Table 1]. Patient perception of disease control was primary good $37.8 \%$ and regular $35.4 \%$.

Patients that continued their follow-up with their rheumatologist (on the clinic face-to-face, electronically or telehealth) or in another clinic were $26.9 \%$, the majority were nonadherent $73 \%$. Persistence to treatment was $82.9 \%$, the main reason to discontinue therapy was lack of prescriptions or medical advice $8.5 \%$ and overall $58.5 \%$ had trouble finding their medicine.

Information regarding covid-19 was mainly obtained by television (health secretary conference) $90.2 \%$, and the least directly from their doctor $4.8 \%$.

Table 1. Survey Results

\begin{tabular}{lll}
\hline & & $\mathrm{N}(\%)$ \\
\hline $\begin{array}{l}\text { Age, mean +/- SD years 52 +/- } 15.9 \\
\text { Female/ Male }\end{array}$ & $78(95.1) / 4(4.9)$ & \\
Diagnoses & RA & $50(61)$ \\
& SLE & $11(13.4)$ \\
& Osteoarthritis & $10(12.2)$ \\
& Other & $11(13.4)$ \\
Disease Control during covid-19 & Excellent & $8(9.8)$ \\
& Good & $31(37.8)$ \\
& Regular & $29(35.4)$ \\
Continued follow-up & Bad & $14(17.1)$ \\
& & $22(26.9)$ \\
(face-to-face, telehealth, other) & & \\
Continued last prescribed treatment & & \\
Reasons to discontinue treatment & Lack of prescriptions/ medical advice & $78(82.9)$ \\
& Lack of availability & $7(8.5)$ \\
& Economic disadvantage & $6(7.3)$ \\
& Fear of getting sick of COVID-19 & $3(3.6)$ \\
"Trouble" finding medicine & & $2(2.4)$ \\
COVID-19 information & Television (Health Secretary conference) & $48(58.5)$ \\
& Social network & $74(90.2)$ \\
& Newspaper/ magazines & $27(32.9)$ \\
& Internet & $14(17)$ \\
& From a doctor & $9(10.9)$ \\
& & $4(4.8)$ \\
\hline & &
\end{tabular}

Conclusion: Patients continue their therapeutic regimen, still many of them have trouble finding their medications, which affects the disease control. Also, despite having a poor disease control (majority between regular and bad) they are not continuing their follow-up care, more objective studies are needed to determine a specific cause.

\section{REFERENCES:}

[1] Pineda-Sic RA, Galarza-Delgado DA, Serna-Pena G, et al. Ann Rheum Dis Epub ahead of print: [20-06-2020]. doi:10.1136/ annrheumdis-2020-218198

[2] Anghel, L. A., Farcaş, A. M., \& Oprean, R. N. (2018). Medication adherence and persistence in patients with autoimmune rheumatic diseases: a narrative review. Patient preference and adherence, 12, 1151-1166. https://doi. org/10.2147/PPA.S165101

Disclosure of Interests: None declared

DOI: 10.1136/annrheumdis-2021-eular.2773

\section{POS1467-HPR SEVERE RESPIRATORY INFECTIONS IN RHEUMATOID ARTHRITIS PATIENTS WITH BIOLOGIC THERAPY. COMPARATIVE STUDY BETWEEN VACCINATED AND NON VACCINATED PATIENTS}

L. Domínguez ${ }^{1}$, P. Rodriguez Cundin ${ }^{2}$, T. Dierssen-Sotos ${ }^{3}$, V. Calvo-

Río $^{1}$, N. Vegas-Revenga ${ }^{1}$, A. Corrales ${ }^{1}$, N. Palmou-Fontana ${ }^{1}$, D. PrietoPeña ${ }^{1}$, M. Calderón-Goercke ${ }^{1}$, M. A. González-Gay ${ }^{1}$, R. Blanco ${ }^{1} .{ }^{1} H U M V$, 